Article

\title{
Miniaturised Infrared Spectrophotometer for Low Power Consumption Multi-Gas Sensing
}

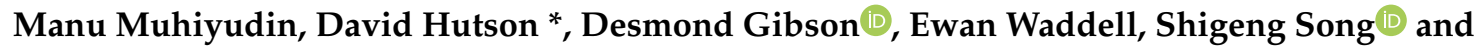 \\ Sam Ahmadzadeh $\mathbb{D}$ \\ Scottish Universities Physics Alliance, Institute of Thin Films, Sensors and Imaging, \\ University of the West of Scotland, Paisley PA1 2BE, UK; Manu.Muhiyudin@meggitt.com (M.M.); \\ des.gibson@uws.ac.uk (D.G.); ewan.waddell@btinternet.com (E.W.); shigeng.song@uws.ac.uk (S.S.); \\ sam.ahmadzadeh@uws.ac.uk (S.A.) \\ * Correspondence: David.hutson@uws.ac.uk; Tel.: +44-(0)-848-3428
}

Received: 7 June 2020; Accepted: 6 July 2020; Published: 9 July 2020

\begin{abstract}
Concept, design and practical implementation of a miniaturized spectrophotometer, utilized as a mid-infrared-based multi gas sensor is described. The sensor covers an infrared absorption wavelength range of 2.9 to $4.8 \mathrm{um}$, providing detection capabilities for carbon dioxide, carbon monoxide, nitrous oxide, sulphur dioxide, ammonia and methane. A lead selenide photo-detector array and customized MEMS-based micro-hotplate are used as the detector and broadband infrared source, respectively. The spectrophotometer optics are based on an injection moulded Schwarzschild configuration incorporating optical pass band filters for the spectral discrimination. This work explores the effects of using both fixed-line pass band and linear variable optical filters. We report the effectiveness of this low-power-consumption miniaturized spectrophotometer as a stand-alone single and multi-gas sensor, usage of a distinct reference channel during gas measurements, development of ideal optical filters and spectral control of the source and detector. Results also demonstrate the use of short-time pulsed inputs as an effective and efficient way of operating the sensor in a low-power-consumption mode. We describe performance of the spectrometer as a multi-gas sensor, optimizing individual component performances, power consumption, temperature sensitivity and gas properties using modelling and customized experimental procedures.
\end{abstract}

Keywords: lead selenide; micro hotplate; linear variable filter; fixed line pass band filters; photo detection; non-dispersive infrared spectroscopy

\section{Introduction}

Non-dispersive infrared (NDIR) sensors are based on mid-infrared absorption spectroscopy [1,2], providing benefits such as cost and sensitivity [1-4], integration as a miniaturised sensor configuration compared to other optical-based gas-sensing techniques [5] such as tunable diode laser absorption spectroscopy [6], photoacoustic spectroscopy [7] and quartz-enhanced photoacoustic spectroscopy [8].

Moreover, NDIR sensors are emerging as a replacement for chemical-based gas sensors [9-13], addressing inherent problems with chemical sensors such as short lifespan due to gradual degradation of the catalyst, high power consumption, susceptibility to gas poisoning and consequent non-fail to safe [9]. The NDIR-based gas sensor described in this work addresses these shortfalls.

Non-Dispersive techniques are finding extensive applications in different fields such as environmental gas monitoring [14], industrial safety [14], medical diagnostics [14-17], demand control ventilation in building air handling systems [18-20], agri-tech [21,22]. NDIR sensors are based on different gases absorbing infrared radiation at uniquely defined wavelengths [22]. When compared with available electrolytic gas detectors, NDIR sensors can provide enhanced accuracy, operate at lower power, are not 
prone to poisoning and have "fail to safe" performance. They also have excellent response times (time constants $<1 \mathrm{~s}$ possible) and excellent sensitivities to gas. The zero drift issues [23] associated with semiconductor gas sensors and problems such as cross-sensitivity, drift and short life-spans associated with electrochemical gas sensors, make optical absorption-based gas sensors an attractive prospect for gas-sensing applications.

Realisation of an NDIR sensor based on spectral differentiation requires the following-(1) a mid-infrared source providing broadband radiation covering the wavelength range of interest, achieved by the use of a blackbody source emitting a broadband infrared spectrum; (2) an optical filter discriminating specific wavelengths from the incident radiation (the present work explores the usage of both fixed line pass band optical filters and linear variable filters for achieving spectral selection); (3) the ability to modulate the source to maximise signal/noise ratio; (4) a photo detector sensitive to IR radiation in the spectral range covering absorption wavelengths of the gases of interest.

The single and multi-gas sensor described here has been developed for mass production, using injection-moulded reflective optics and CMOS-based light source and detector manufacture, combined with miniaturized electronics, reducing overall size of the actual multi-gas sensor size to within $25 \times 25 \times 25 \mathrm{~mm}$.

\section{Materials and Methods}

\subsection{Optical Design and Construction}

An optical design based on a Schwarzschild configuration [24] magnifies the optical source output, matching the spatial input to a lead selenide array of detectors [25]. An optical filter (described in detail in Section 2.4) placed on the detector array provides spectral discrimination across the array elements. A basic representation of the sensor is provided in Figure 1.

An optical light source is a spatially extended micro-hotplate with a $0.6 \times 0.2 \mathrm{~mm}$ active area size (Section 2.2), magnifies source output by 10 and 5, respectively, in length and width, respectively, to $6 \times 1.0 \mathrm{~mm}$, matching the detector array size. Overall gas absorption pathlength is $60 \mathrm{~mm}$ (achieves required absorption over a wide range of gases-see Section 2.6), comprising a three-piece injection moulded (blend of polycarbonate and platable acrylonitrile butadiene styrene) folded optic, as shown in Figure 1b. All reflective surfaces are sputter gold coated, providing high mid infrared reflectivity (typically $98 \%$ per surface). Figure 1c shows the actual three pieces injection moulded assembly beside a United Kingdom 50 pence piece (diameter $23 \mathrm{~mm}$ ). Overall, sensor assembly dimensions are $25 \times 25 \times 25 \mathrm{~mm}$, providing a miniaturised NDIR multi-gas sensor compared with other optical gas-sensing approaches [3-5]. 


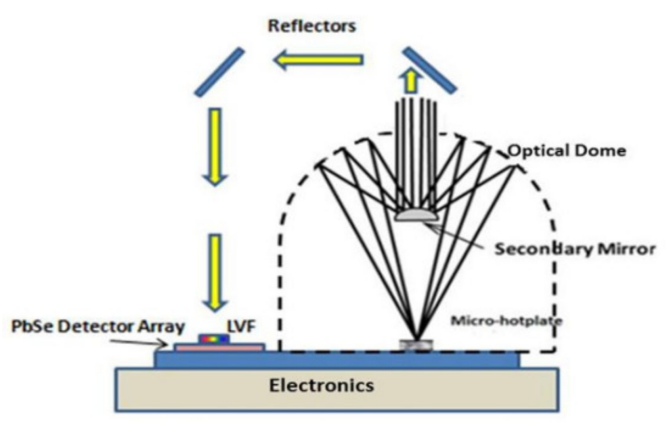

(a)

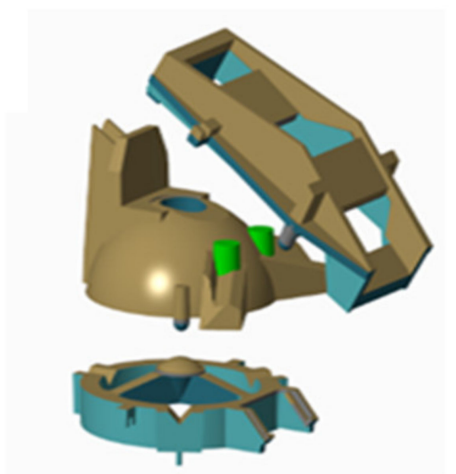

(b)

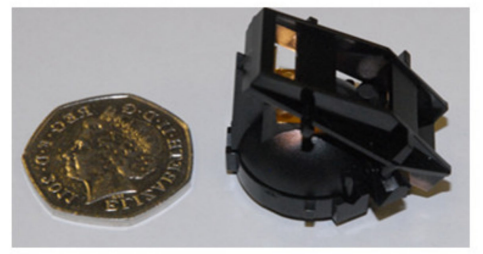

(c)

Figure 1. (a) Schematic of the multi-gas sensor optics; (b) exploded view of the three-piece optical assembly; (c) assembled injection moulded optics (UK 50 pence piece shown for scale-23 mm diameter).

\subsection{MEMS Micro-Hotplate as the Infrared Source}

The micro-hotplate [26-28] used here is constructed using polysilicon (Poly-Si) thin-film sandwiched between two silicon nitride substrates. Aluminum metal is used as the conducting electrode to the micro-heater. Figure 2a shows the electrodes connecting to the polysilicon membrane showing the cut-out sections or slits. When electrically energized, the micro-heater initiates warm-up due to electro-thermal interaction. There will be significant conduction losses from the body to the substrate and also some convection losses [29]. Energy will also be radiated from the surface, providing an effective blackbody (broadband) infrared source. Figure $2 b$ shows the intensity distribution of the emitted radiation.

The ideal micro-hotplate characteristics are low thermal mass, temperature uniformity, low power consumption and resistance to low pressure and high temperatures.

Non-uniform voltage equipotential lines near edges of the slits cause a greater pull of electrons and consequently, higher current density. This results in increased temperature between the slits. The micro-hotplate length is customized to $0.6 \mathrm{~mm}$ length, providing magnification to $6 \mathrm{~mm}$ at the detector array (see Section 2.3). The broadband spectrum produced by the micro hotplate provides the required signal spread over all elements of the lead selenide infrared detector array. The hotplate is operated in a constant voltage mode, using a circuit developed specifically to provide a battery compatible electromotive force of $<5 \mathrm{~V}$. 
A future publication will describe the MEMS hotplate design and fabrication in detail.

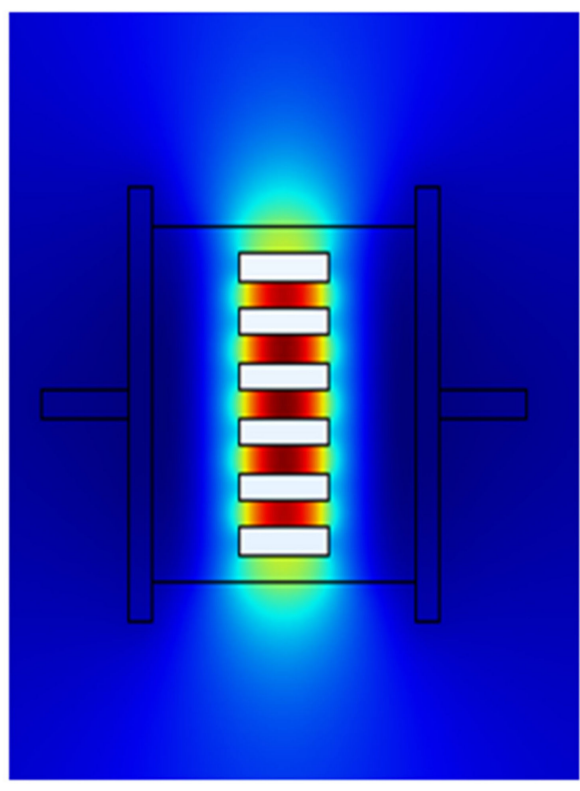

(a)

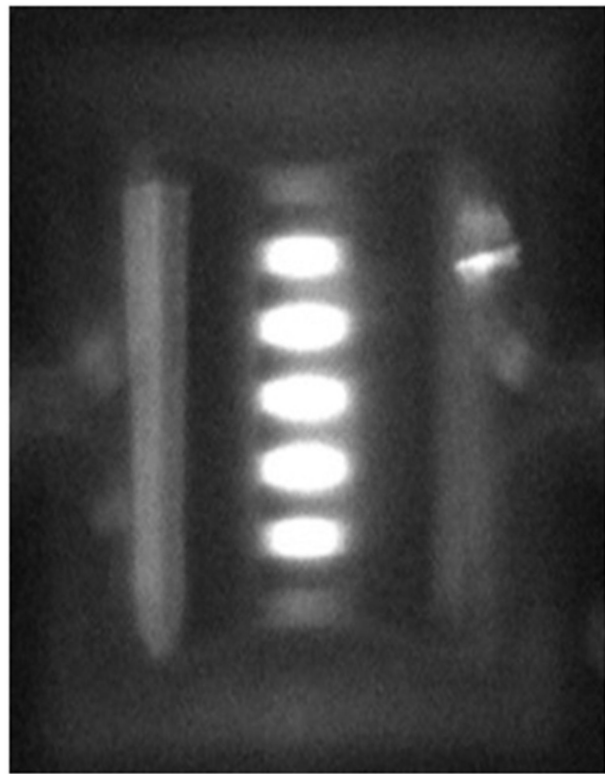

(b)

Figure 2. (a) Modelled Micro Hotplate showing solid contours for temperature of the microheater with PolySi layer built on a Si3N4 substrate (b) IR-camera image of the actual Micro Hotplate.

\subsection{Infrared Detector}

Photoconductive lead selenide is used as the infrared detector, in the form of an 8 elementarray $-1.0 \mathrm{~mm} \times 0.8 \mathrm{~mm}$ for each pixel of the array. The temperature sensitivity of lead salt detectors [30,31] requires real-time temperature compensation, achieved using a built-in reference channel.

With the optical filter(s) integrated onto the detector array, the drop in output of specific channel(s) can be made to correspond to specific gas detection, as shown in Figure 3. The array element with zero change in output due to infrared absorption is assigned for the reference channel. The reference channel is used for drift compensation due to temperature changes and path length variation. This improves sensor accuracy and repeatability.

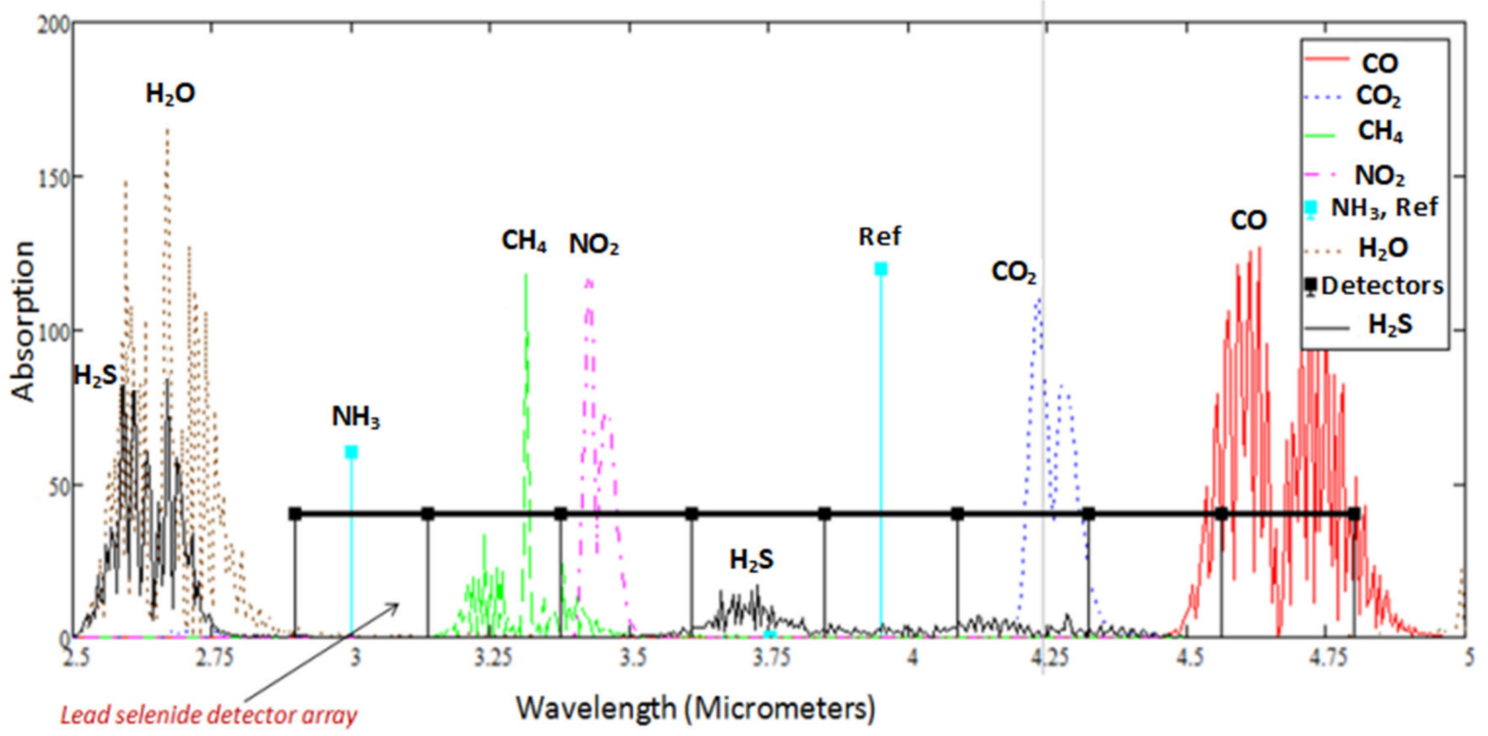

Figure 3. Lead selenide detector alignment with gas absorption spectra. 
A $60 \mathrm{~mm}$ path length demonstrator developed with transmissive bulk optics is shown in Figures 4a and 5. A single-element lead selenide detector was used during testing, with a micro hotplate point source providing the input infrared radiation at $4 \mathrm{~Hz}$ and $12 \mathrm{~Hz}$ frequencies. The response of the system was recorded at a time constant of $12 \mathrm{~ms}$.

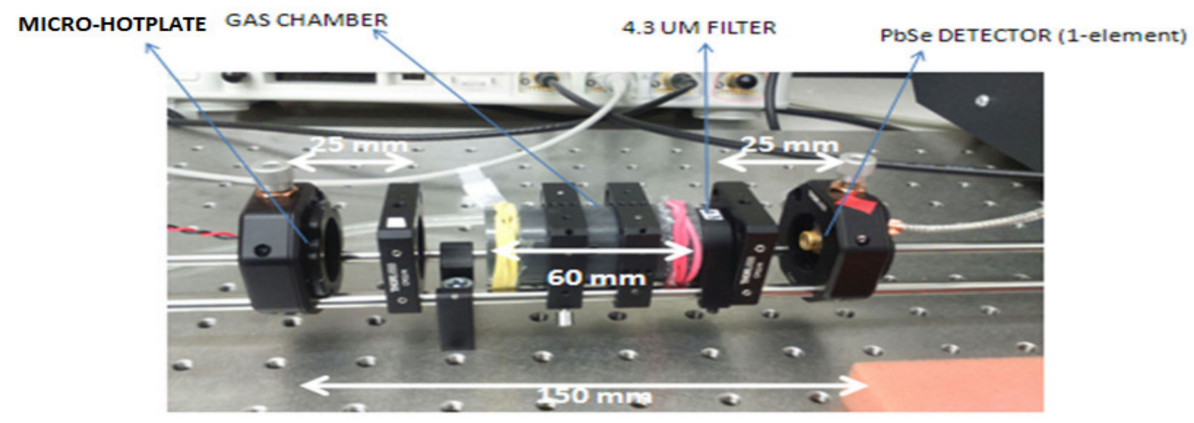

(a)

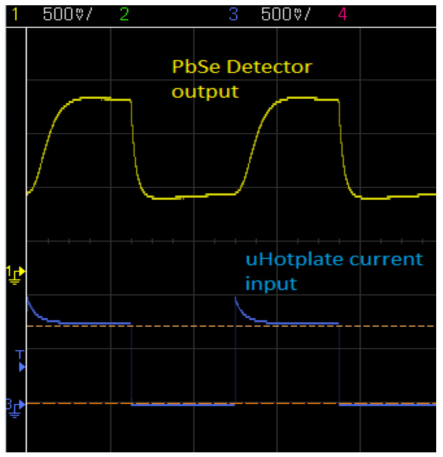

(b)

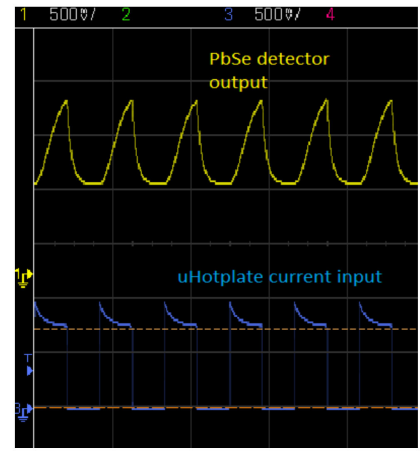

(c)

Figure 4. (a) Demonstrator setup for gas detection with $25 \mathrm{~mm}$ optical lenses, (b) output with the hotplate driven with a $4 \mathrm{~Hz}$ square wave, and (c) output with hotplate driven with $12 \mathrm{~Hz}$ square wave.

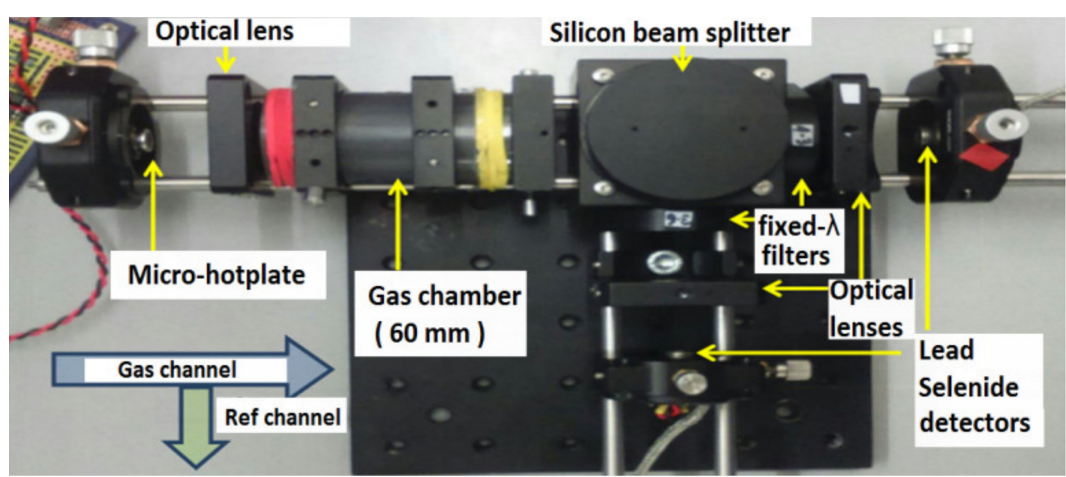

Figure 5. The demonstrator utilizing two single-element lead selenide detectors for the gas and reference channels.

\subsection{Optical Filter}

Both commercial as well as in-house manufactured fixed filters were used as spectral differentiators for the experimental needs. Modelling (Section 2.6) describes the ideal pass band characteristics of the filter for the optimal performance during gas detection. 


\subsubsection{Linear Variable Filters}

Linear variable filters (LVF) are spatially variable optical band pass filters, in which the center wavelength changes with position in a linear manner along one direction of the filter. The LVF used in this work was fabricated at the University of the West of Scotland using a unique and volume-scalable technology [32-34]. The manufactured LVF has a spectral range of 2.9 to $4.8 \mu \mathrm{m}$ with a pass band width of $1.5 \%$. and peak transmission of $70 \%$, thereby providing wavelength discrimination across the detector array and covering the range of gases of interest (e.g., $\mathrm{CH}_{4}, \mathrm{~N}_{2} \mathrm{O}, \mathrm{CO}_{2}, \mathrm{CO}$ ).

\subsubsection{Fixed-Line Optical Pass Band Filter}

Optical pass band filters transmit only a particular band of wavelength and blocks the other wavelengths on either side of the band. The band pass can be anywhere from less than an Ångström to a few hundred nanometers and such filters are usually manufactured by combining a long pass and a short pass optical filter. Both commercial and in-house manufactured optical pass band filters were used for this work.

\subsection{Electronics}

As described in Section 2.1 the injection-molded optics use a Schwarzschild-based optical dome design [24] where the source is magnified, matching the detector array spatial configuration. Associated electronics controls the micro hotplate input and up to 8 detector channels. A 16-bit ADC and 12-bit DAC are used for measurements and temperature offset corrections, respectively. An ultra-low power FPGA is utilized in the design, which is used to control the A-to-D converter, D-to-A converter, input multiplexer and also the hot plate pulsing. The processor clocks the FPGA at $42 \mathrm{MHz}$, which manages the system timing. A GUI is developed which can set the pulse-width, pulse-decay time, collect ambient temperature measurements and the offset measurements (which is a direct measure of the resistance change in the detector channel due to temperature sensitivity). The hot plate is pulsed by a constant voltage driver circuit and mirrors the processor DAC output voltage. The data is read out through a serial interface.

\subsection{Modelling}

Mathcad 15.0 is used for the modelling and provides a convenient and dynamic platform to approach the complex modelling of the sensor. The sensor possesses a net optical path length of $60 \mathrm{~mm}$. Gas absorption data are imported into the MATHCAD model from the HITRAN 2012 data base in Spectral Calc online spectral modelling tool. A total of 600 data points of wavelength and absorption strength data for each of the gases are extracted locally for modelling.

A MEMS-based micro hotplate with doped polysilicon as the active heating element is modeled as the broadband infrared source. The dimension of the polysilicon layer is $600 \times 650 \times 1 \mu \mathrm{m}$, which is sandwiched between layers of Silicon Nitride and Silicon Dioxide substrates. By Planck's law for electromagnetic radiation, the net spectral radiant exitance or the net black body radiation emitted into a hemisphere by the micro hotplate at a certain temperature $\mathrm{T}$ and wavelength $\lambda$, in power per unit area per wavelength interval is given by:

$$
\mathrm{W}_{\text {Planck }}(\lambda, \mathrm{T})=\frac{2 \pi \mathrm{h} \mathrm{c}^{2}}{\lambda^{5}}\left(\mathrm{e}^{\left(\left(\frac{\mathrm{hc}}{\lambda \mathrm{KT}}\right)-1\right)}\right)^{-1}
$$

where $\mathrm{h}$ is the Planck's constant, $\mathrm{c}$ is the speed of light, $\mathrm{k}$ is the Boltzmann's constant and $\lambda$ the wavelength of the electromagnetic radiation. The net source spectral radiant power is then estimated at a specific source temperature $T_{S}$, by integrating the total black body radiation over the whole area of the micro hot plate. It is modeled as shown below in Figure 6 . 


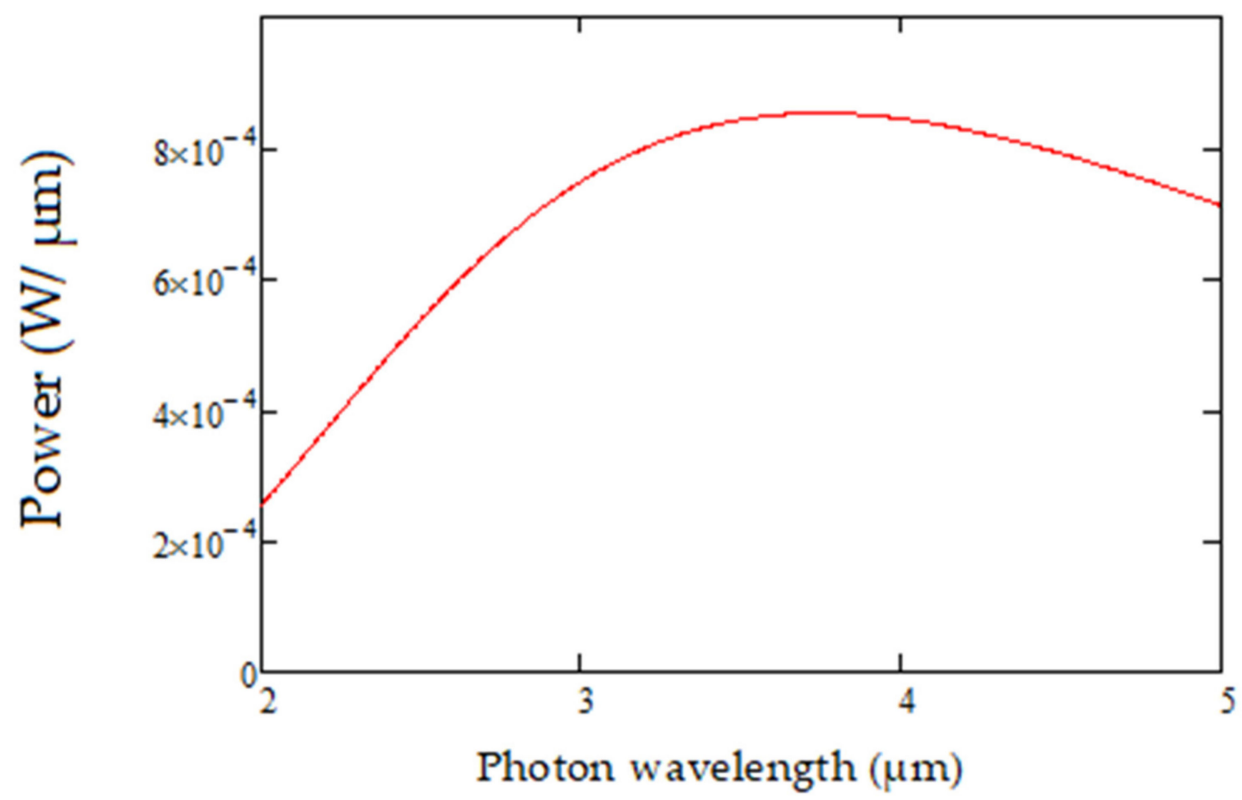

Figure 6. Source spectral radiant power for the micro-hotplate source.

The photoconductive Lead Selenide detector is modeled for its specific detectivity ( $D^{*}$ ) within the MWIR detection range of 2 to $5 \mathrm{um}$. The Lead Selenide detector is used in the form of an 8-detector array $-1.0 \mathrm{~mm} \times 0.8 \mathrm{~mm}$ for each element of the array. Lead Selenide is highly temperature-sensitive and one of the detector array elements is designated as the reference channel to compensate for temperature drifts and cross-sensitivities during gas measurements. Noise factors such as Johnson-Nyquist noise and dark current noise are also incorporated into the detectivity estimation.

Specific detectivity $\left(D^{*}\right)$ for a wavelength $\lambda$ and detector temperature $T$ is estimated as:

$$
\mathrm{D}^{*}{ }_{\lambda \mathrm{T}}(\lambda, \mathrm{T})=\mathrm{D}_{\mathrm{PR}} \times \mathrm{S}_{\mathrm{PD}}(\lambda, \mathrm{T})
$$

DPR is a parameter dependent on the noise spectral density of the sensor, area of the detector array element and the detection bandwidth. $\mathrm{SPD}_{\mathrm{PD}}(\lambda, \mathrm{T})$ is a function of the responsivity of the detector. The detector responsivity, is modelled as:

$$
\mathrm{S}_{0 \mathrm{PD}^{(\mathrm{T})}}=\frac{\eta_{\mathrm{detPD}} \times \mathrm{q}_{\mathrm{e}} \times \mathrm{G}_{\mathrm{pc}}(\mathrm{T})}{\mathrm{h} \times \mathrm{c}}
$$

where $\eta$ is the quantum detector efficiency, which is the ratio of the number of electrons collected by the photoconductor to the total number of incident photons, $\mathrm{q}_{\mathrm{e}}$ is the charge of an electron, $\mathrm{G}_{\mathrm{pc}}(\mathrm{T})$ is the photoconductive gain at temperature $T, h$ is the Planck's constant and $\mathrm{c}$ is the speed of light. $\mathrm{G}_{\mathrm{pc}}$ is not necessarily 1 . This is strongly temperature-dependent, and the power temperature dependence shown below is on the basis of temperature dependence of mobility, due to optical phonons which are usually dominant at moderate temperatures.

The Detectivity $D^{*}$ at $25^{\circ} \mathrm{C}$ for a specific detector temperature $T_{D}$ is thus given by:

$$
\mathrm{D}^{*} 25\left(\lambda, \mathrm{T}_{\mathrm{D}}\right)=\frac{\mathrm{D}^{*}{ }_{\lambda \mathrm{T}}\left(\lambda, \mathrm{T}_{\mathrm{D}}\right)}{\mathrm{N}_{\mathrm{D}^{*} 25}}
$$

where $\mathrm{N}_{\mathrm{D}^{*} 25}$ is the Noise Spectral Density at $25^{\circ} \mathrm{C}$.

The net detectivity will be the area under the curve, integrating it over the detectable wavelength range. At $25^{\circ} \mathrm{C}$, the detectivity $\mathrm{D}^{*}$ is calculated as $2.939 \times 10^{9}$ Jones (slightly higher than the datasheet value of $2 \times 10^{9}$ Jones for the commercial Lead Selenide detector array used for testing).

The detector response is modeled for its detectivity $\mathrm{D}^{*}$, as shown in Figure 7 below. 


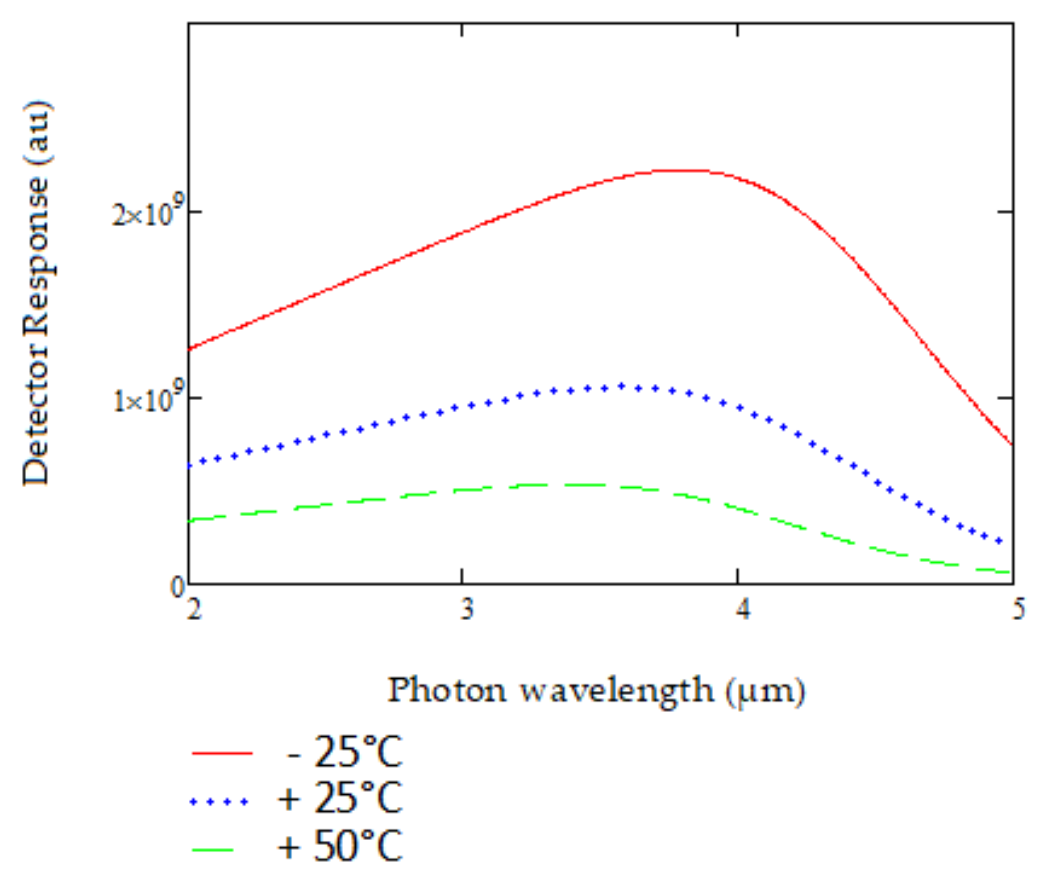

Figure 7. Lead selenide detector response modelled at different temperatures in the 2 to $5 \mu \mathrm{m}$ range.

The variation of detectivity $\mathrm{D}^{*}$ with temperature is then modelled for $0{ }^{\circ} \mathrm{C}, 25{ }^{\circ} \mathrm{C}$ and $50{ }^{\circ} \mathrm{C}$, as shown in Figure 7. The ability to achieve spectral control for both the source and the detector is critical for ensuring accurate compensation while detecting gas. The source-detector product is of particular importance and represented as shown in Figure 8, fitting into the MWIR spectral range of interest.

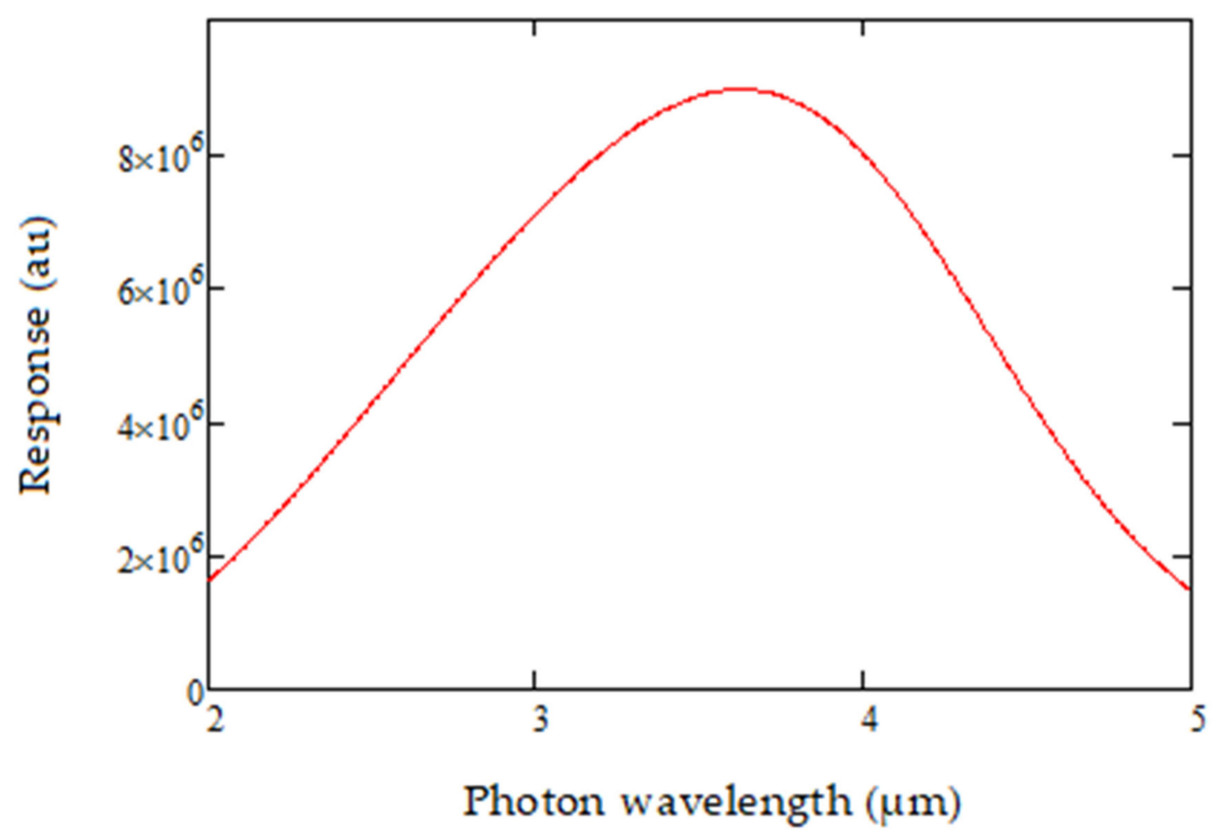

Figure 8. Source-Detector product over the detection range of interest.

The model can switch between a linear variable filter and a fixed-line pass band filter to be the spectral differentiator in the sensor assembly. The manufactured LVF's have a spectral range of 2.9 to $4.8 \mu \mathrm{m}$, with a pass band width of $1.5 \%$ and peak transmission of $70 \%$. The LVF transmision is modelled as a Gaussian distribution around the central wavelength of interest. The transmittance at 
the centre of each of the detector element is averaged to yield a spectrum shown in Figure 9-with lower average transmittance, as expected, at the lower end of the wavelength range and higher average transmittance at upper wavelengths [35].

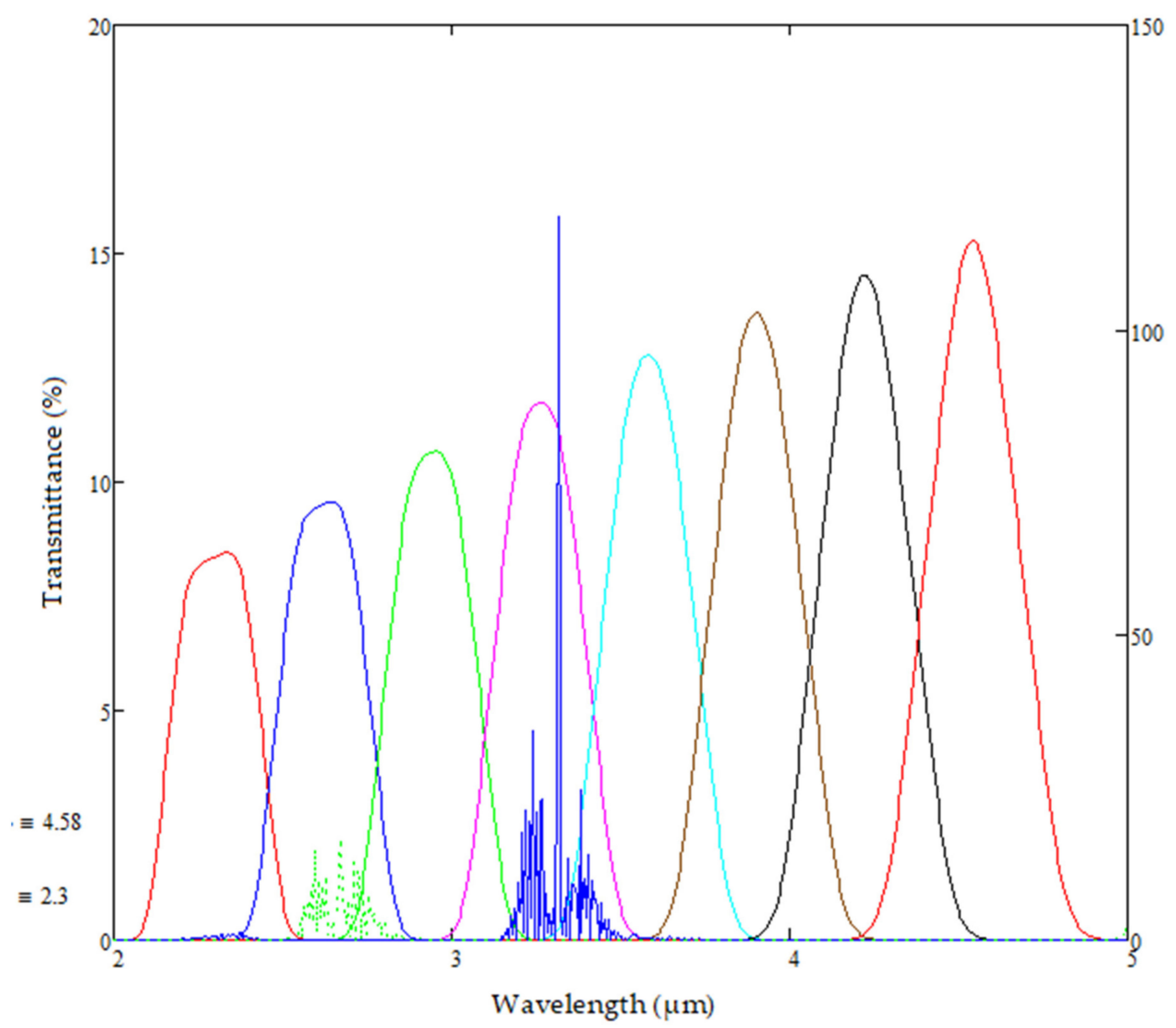

Figure 9. Modelled average spectra over each element of the lead selenide detector array after placement of linear variable filter.

The fixed pass band filters are modelled to match ideal band pass characteristics suited for improved gas sensitivities, as well as to emulate available commercial fixed filter specifications [36].

The reference channel filter's central wavelength is chosen from modelling design, to be as close to the signal channel filter's-as shown in Figure 10. This ensures temperature shifts have minimal effects on the performance of the filters and the detector output.

When using a fixed pass band optical filter, issues such as light leakage onto adjacent channels, reduced transmittances at lower wavelengths, inherent to an LVF, are significantly reduced using fixed-line pass band filters over the detector elements, providing enhanced gas sensitivity. 


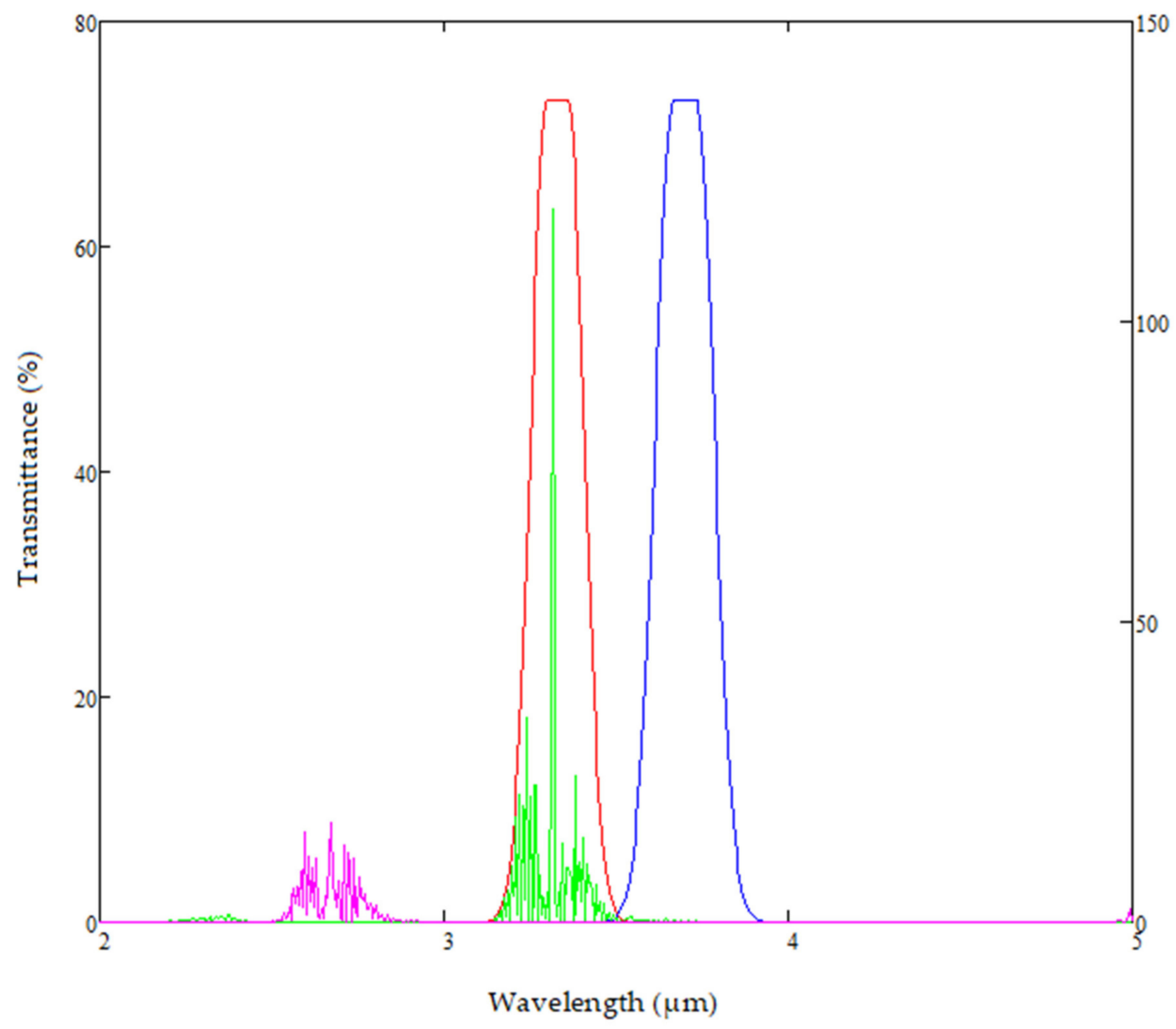

Figure 10. Signal and Reference filter placement using fixed pass band optical filters.

The Source-Detector-Filter product is then modelled to consolidate accurate placement of the filter and provide baseline model performance before gas introduction as shown in Figure 11.

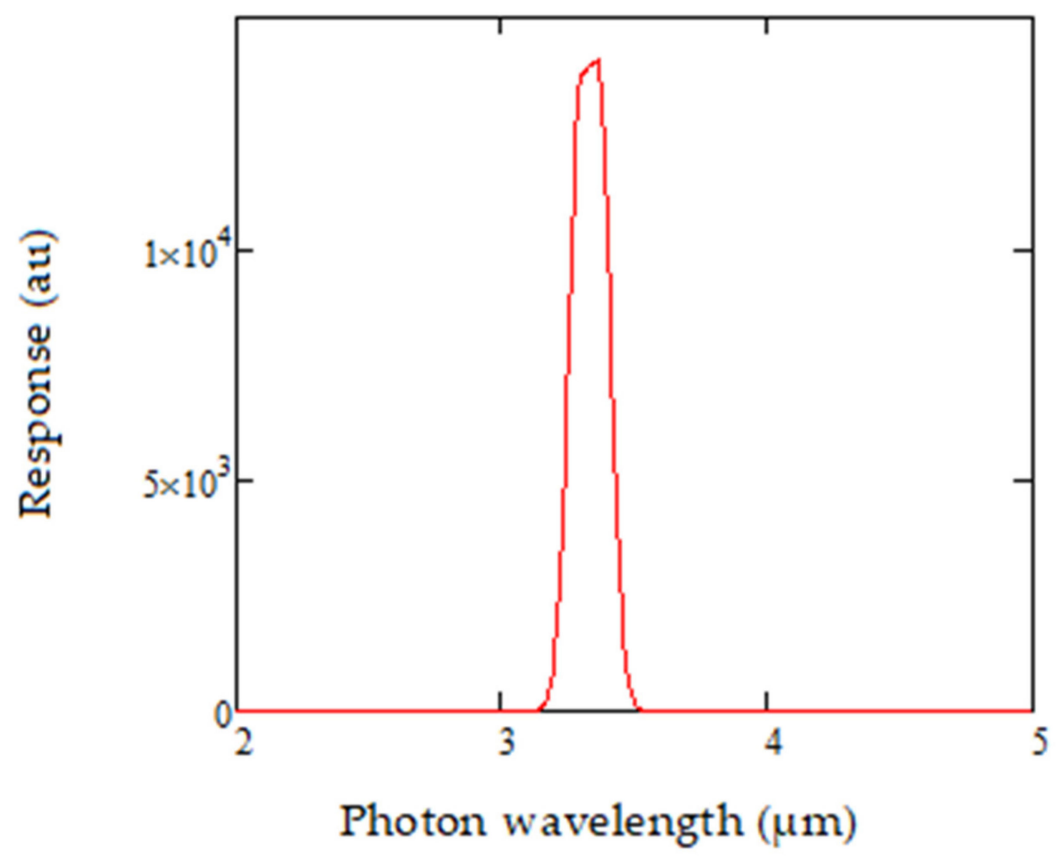

Figure 11. Source-Detector-Filter product for methane gas detection. 


\section{Results}

\subsection{Absorption Modelling Calculation}

The gas cell is then modelled by calculating transmittance through the gas of interest. A total of 600 data points is chosen within the detector wavelength range and the product of transmittance and source-detector-filter is calculated at each of these points and integrated over the wavelength range. The transmittance is calculated using Beer-Lambert's law, which determines the relation between absorbance and concentration of the infra-red absorbing medium, which, in this case, are the gas molecules of interest. Methane detection is explored in detail, in the context of this paper, and water vapour is chosen as the back-filling gas. Transmittance, which is the ratio of the intensity of IR after absorption to the intensity of IR after absorption, is estimated as:

$$
\mathrm{T}_{\mathrm{CON}}=\mathrm{e}^{-\left(\alpha_{\text {gas }_{1}}\right) \times \mathrm{c} 1 \times \mathrm{L}_{\text {cell }}} \times \mathrm{e}^{-\left(\alpha_{\mathrm{gas}_{2}}\right) \times \mathrm{c} 2 \times \mathrm{L}_{\text {cell }}}
$$

where $\alpha_{\text {gas } 1}$ and $\alpha_{\text {gas2 }}$ are the molar absorptivities of the target gas and the back gas, respectively. $\mathrm{L}_{\text {cell }}$ is the optical path length of the gas cell and c1, $c 2$ are the gas concentrations of the target and the back gas.

The effective detected signal generated can thus be estimated over the entire wavelength range of detection as:

$$
\mathrm{S}=\mathrm{O} \times \sum(\mathrm{T} \times \mathrm{F} \times \mathrm{S} \times \mathrm{D})
$$

where $\mathrm{O}$ is the optical throughput of the sensor

$\mathrm{T}$ is TCON, the transmittance through gas

$F$ is the effective optical filter transmittance

$S$ is the net source spectral strength

$\mathrm{D}$ is the net detectivity of selected detector channel

The signal strength is calculated in a similar manner, for the chosen detector reference channel as well. The Signal to Reference ratio is normalized and plotted against the gas concentration as shown in Figure 12 and the slope of the curve is estimated to determine the sensitivity of gas detection. The effects of temperature on the sensitivity measurements can also be seen, which makes the specifications of the chosen signal and reference filters even more critical for maintaining an acceptable level of deviation.

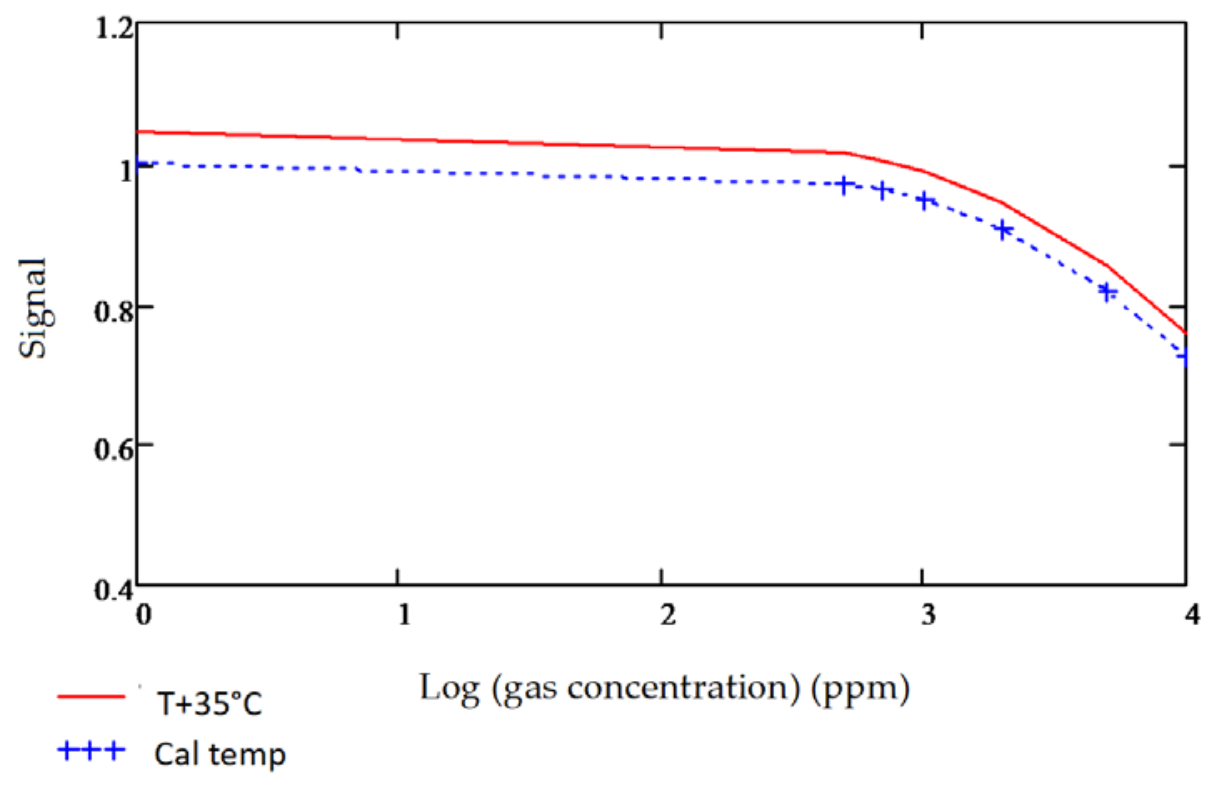

Figure 12. Source-Detector-Filter product for methane gas detection. 
The gas sensitivity to Methane was modelled as follows in Table 1:

Table 1. Modelled methane gas sensitivity values for different concentration ranges.

\begin{tabular}{cc}
\hline Measurement Range & $\begin{array}{c}\text { Accuracy } \\
\text { of Measurement }\end{array}$ \\
\hline 0 to $100 \mathrm{ppm}$ & $\pm 25 \mathrm{ppm}$ of measured reading \\
100 to $1000 \mathrm{ppm}$ & $\pm 1 \%$ of measured reading \\
21,000 to $1,000,000 \mathrm{ppm}$ & $\pm 1.1 \%$ of measured reading \\
\hline
\end{tabular}

The integration time or the time for making a precise single measurement is dependent on the number of measurement pairs chosen from the peak and trough of the detector response pulse, the total number of pulses (the frequency of operation of the micro-hotplate). The slope of the Signal to Reference curve is then taken and compensated for quantization noise, to determine the measurement accuracy of the sensor to a specific gas, in this case, methane.

Similarly, other gases of interest such as carbon dioxide, carbon monoxide, nitrogen dioxide, sulphur dioxide, ammonia and benzene are modelled and the signal and reference channel filter characteristics are varied to get down to detection accuracies of the required levels for each of the gas.

\subsection{Power Consumption}

The multi-gas sensor can be operated at a very low power in the order of milli Joules, depending on the frequency of operation of the source and the number of data samples from each pulse required to maintain an acceptable level of accuracy. For a $1 \mathrm{~Hz}$ operation of the sensor, the energy consumed for toggling the hot plate $\mathrm{ON}$ and OFF can be as low as $13 \mathrm{~mJ} / \mathrm{s}$. This is excluding the current drawn by the analog circuitry during the microcontroller's IDLE state and ADC (Analog-to-Digital Converter) activation stages. For measurement of individual gases, the total energy per measurement depends on the number of samples from the detector pulse used for making a meaningful measurement, which would in turn, depend on the total integration time for measurement. Table 2 shows the average power consumption charts for gas measurements and Figure 13 illustrates the control of pulse-width as an efficient method to reduce energy consumed per measurement.

Table 2. Power requirements for a single measurement of different gases.

\begin{tabular}{cccccc}
\hline Gas & $\begin{array}{c}\text { Samples } \\
\text { Required }\end{array}$ & $\begin{array}{c}\text { Pulses } \\
\text { Required }\end{array}$ & $\begin{array}{c}\text { Total Time } \\
(\mathbf{s})\end{array}$ & $\begin{array}{c}\text { Total Energy } \\
(\mathbf{m} \mathbf{)})\end{array}$ & $\begin{array}{c}\text { Average Power } \\
\text { Consumption }(\mathbf{m W})\end{array}$ \\
\hline $\mathrm{CO}_{2}$ & 100 & 1 & 1 & 13 & 13 \\
$\mathrm{CH}_{4}$ & 100 & 1 & 1 & 13 & 13 \\
$\mathrm{CO}$ & 100,000 & 1000 & 1000 & 13,000 & 13 \\
$\mathrm{NO}_{2}$ & 100,000 & 1000 & 1000 & 13,000 & 13 \\
$\mathrm{H}_{2} \mathrm{~S}$ & $1,000,000$ & 10,000 & 10,000 & 13,000 & 13 \\
$\mathrm{NH}_{3}$ & $1,000,000$ & 10,000 & 10,000 & 13,000 & 13 \\
\hline
\end{tabular}

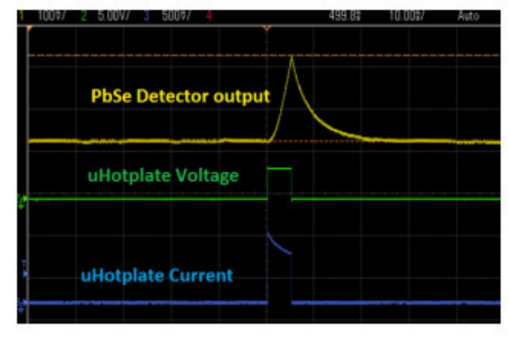

(a)

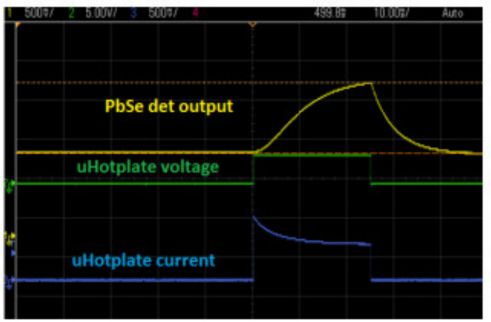

(b)

Figure 13. (a) System output with hotplate pulsed at $5 \mathrm{~ms}$ and (b) System output with hotplate pulsed at $25 \mathrm{~ms}$. 


\subsection{Gas Concentration Tests}

Gas concentration tests were conducted within a custom-made gas chamber. Using a mass flow controller and nitrogen as the inert gas, experiments were conducted under a constant temperature. The gas chamber volume was chosen to be small, per design, to establish lower stabilization times after the introduction of gas.

Mass flow meters enabled gas mixing and the ratio with the inert gas, in this case, Nitrogen, was used to control the percentage/ppm levels of the target gas to be tested. Carbon dioxide, methane and carbon monoxide were tested using the setup shown in Figure 14.

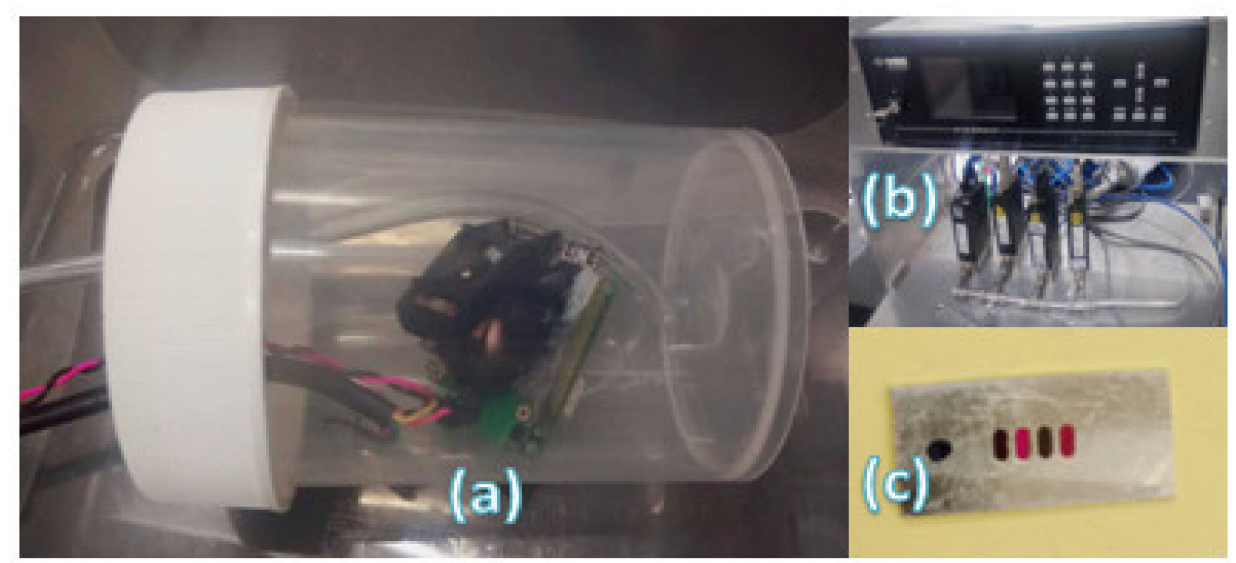

Figure 14. (a) Gas sensor custom-built chamber; (b) Mass Flow Controllers for gas mixing; (c) Aluminium-based filter array holders for testing fixed-line passband filters.

Using assembled fixed-line filter array as the spectral differentiator (as shown in Figure 15), the following results were obtained:

(a) Methane was detectable at 100 ppm, 500 ppm and 25,000 ppm (below lower explosive limit)—but longer sampling times and faster sampling techniques are required as these improve detection by compensating for the noise fluctuations in the system. Figure 15 shows how the PbSe detector output indicated 2.5\% Methane detection. In addition to methane, the following performance for $\mathrm{CO}_{2}$ and $\mathrm{CO}$ observed:

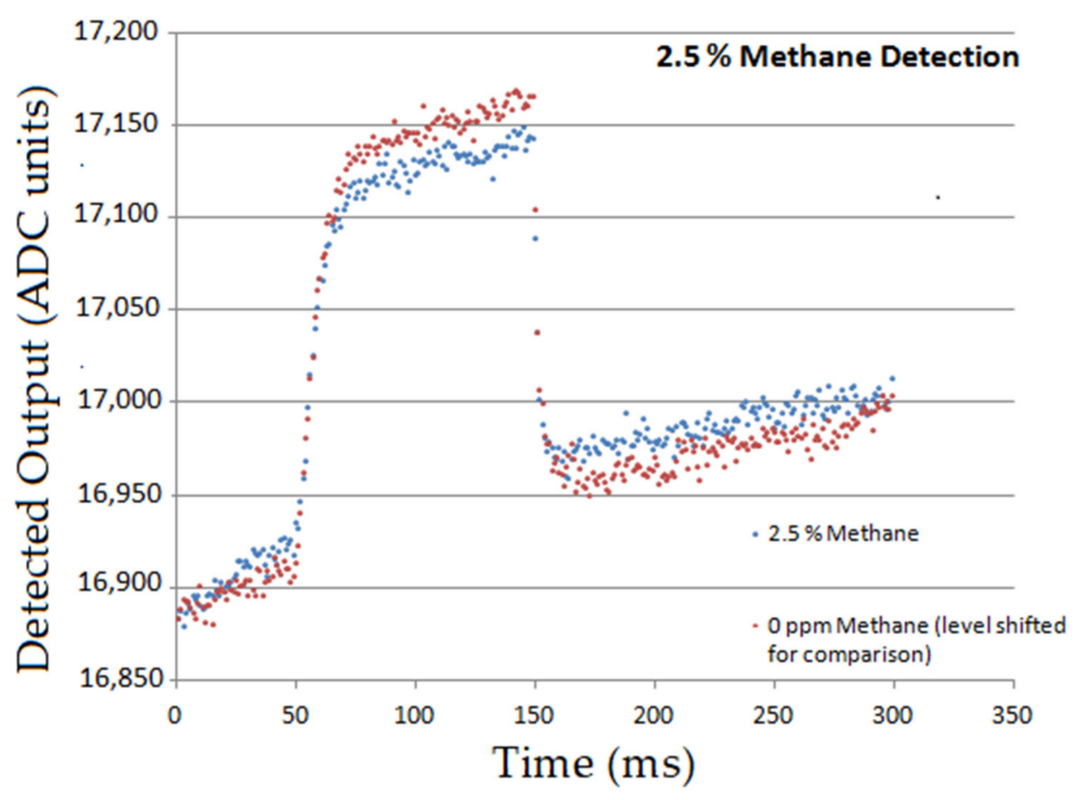

Figure 15. PbSe detector output demonstrating 2.5\% Methane detection. 
(b) $\mathrm{CO}_{2}$ : Very good detection at $50 \mathrm{ppm}, 100 \mathrm{ppm}$ and $170 \mathrm{ppm}$.

(c) CO: Tested at $50 \mathrm{ppm}$ and tests did not show evident detection due to lowered $\mathrm{S} / \mathrm{N}$ levels in the system. CO detection is more difficult due to the centre wavelength at $4.65 \mu \mathrm{m}$ lying on the falling edge of the lead selenide detector $D^{*}$-lambda curve.

\subsection{Temperature Sensitivity}

It was observed during gas sensitivities modelling that the bandwidth and central wavelength of the fixed filters used are critical to maintaining an acceptable level of temperature offset between the signal and reference channel output signals. The reference channel is designated mainly to account for temperature-related corrections. Inherent output shifts due to the nature, quality and position of the filter used are disruptive and should be corrected by strategically designing the signal and reference filters for each gas. The importance of this is illustrated in carbon monoxide detection modelling, as shown in Figure 16a,b below.

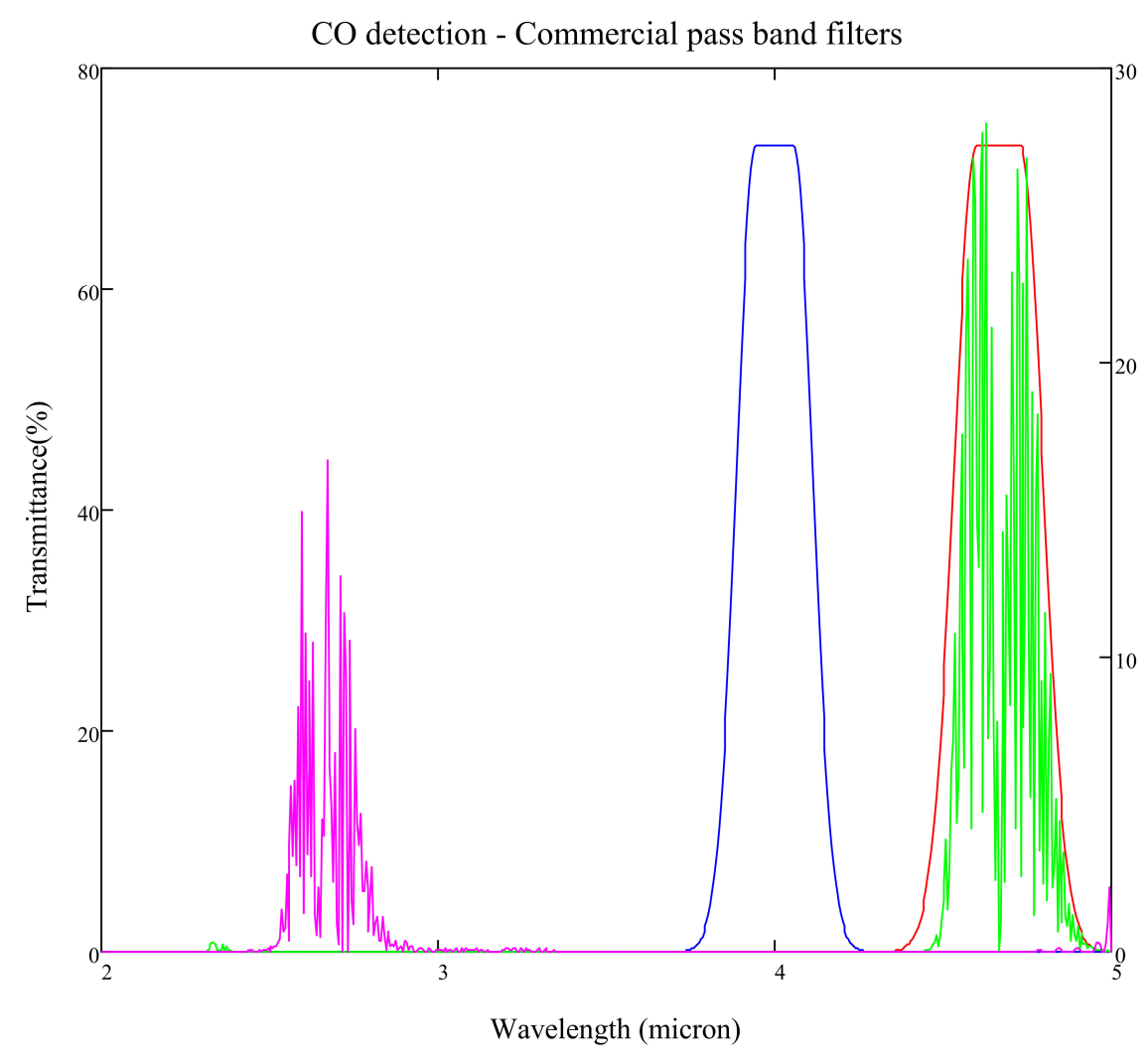

(a)

Figure 16. Cont. 


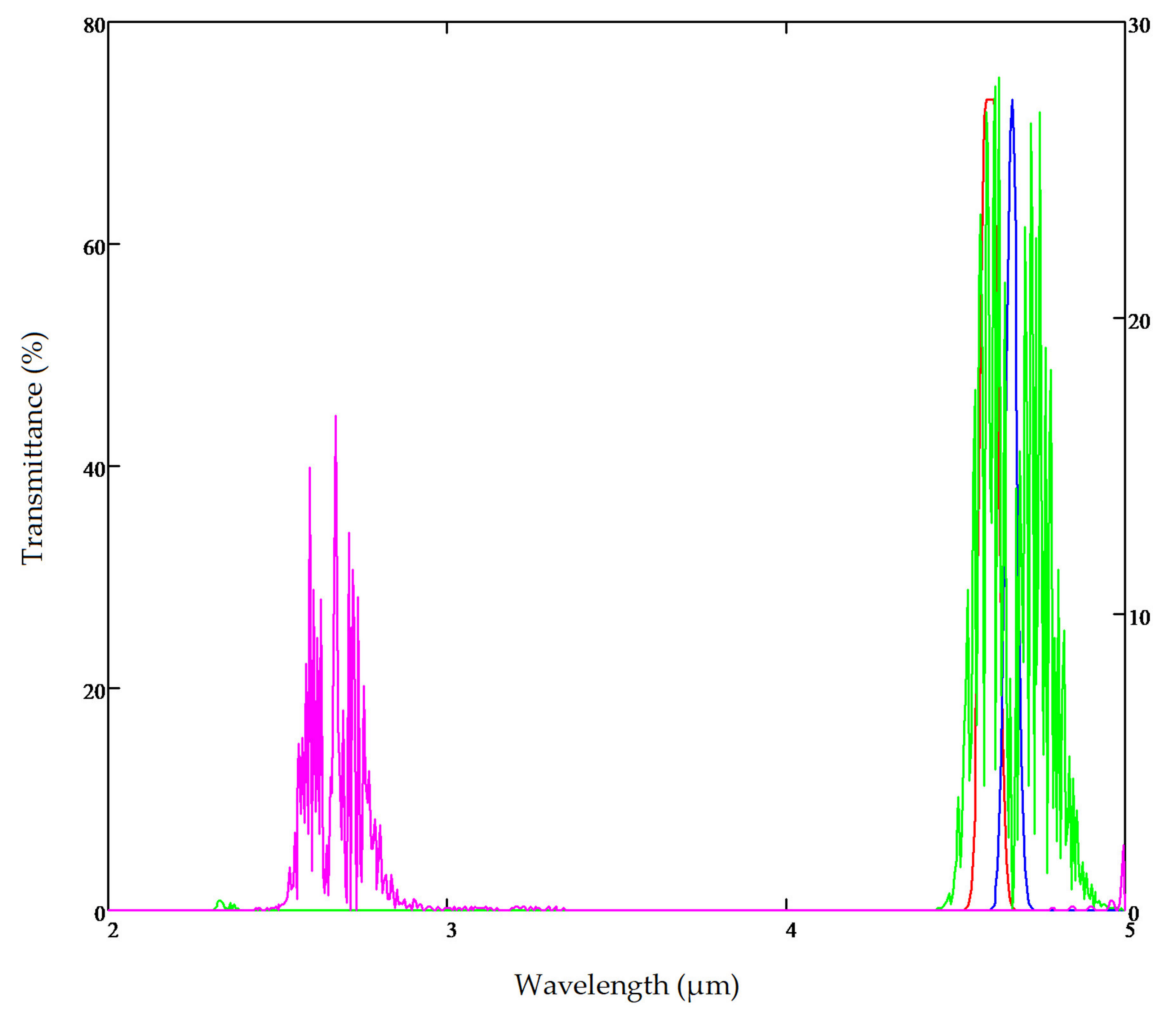

(b)

Figure 16. (a) Design A: CO filter transmission using $480 \mathrm{~nm}$ wide commercially available signal [37] and reference filters. (b) CO filter transmission using $100 \mathrm{~nm}$ wide in-house designed signal filter and reference filters [33].

The gas detection accuracies for both Design A and Design B (Figure 16a,b) were modelled at room temperature $25^{\circ} \mathrm{C}$ and an increased temperature to $60^{\circ} \mathrm{C}$. As observed from the following Figures 17 and 18, the temperature effects on the fixed pass band filters and its resultant impact on the gas sensitivities are adverse when using wider commercial pass band filters, which did not have optimal reference central wavelengths.

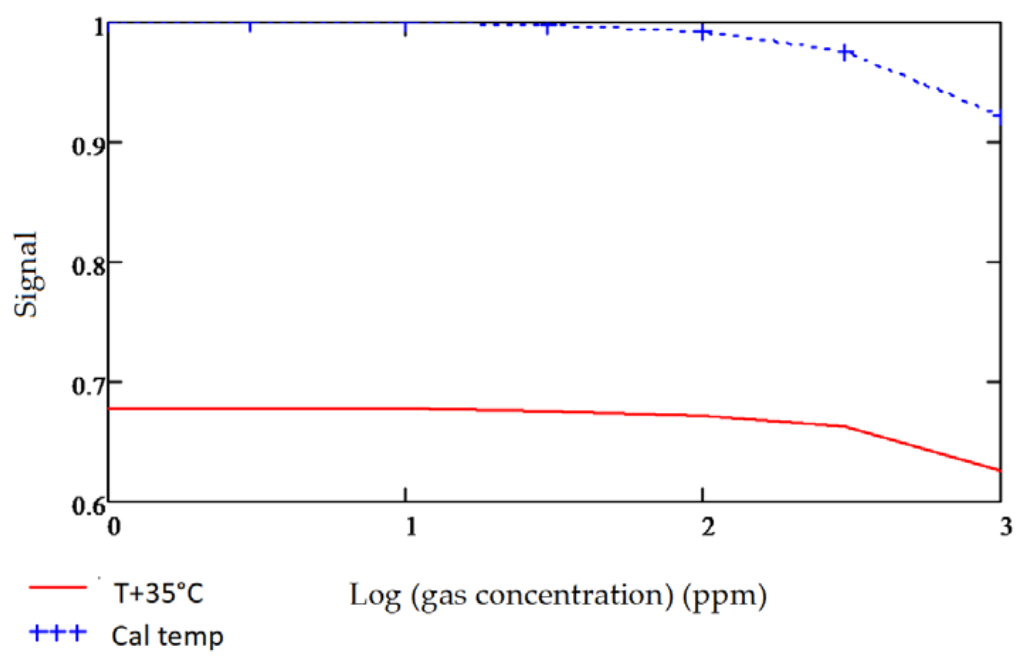

Figure 17. Design A: Detected lead selenide output with commercial signal and reference filters. 


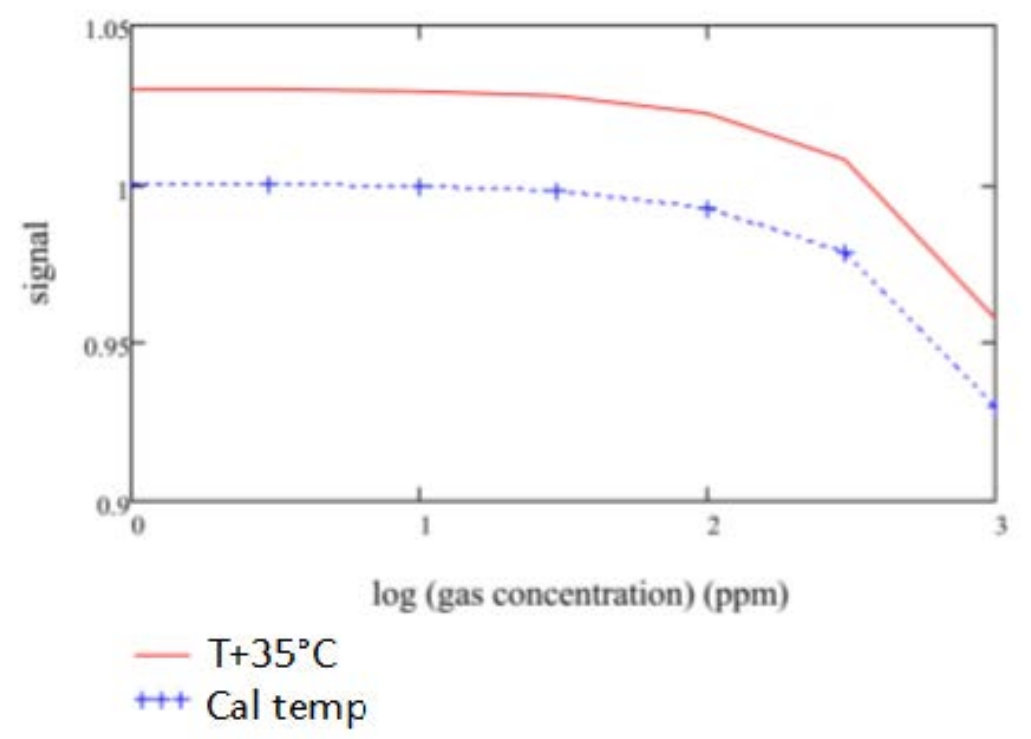

Figure 18. Design B: Detected lead selenide output with ideally designed signal and reference filters.

The results showed that for each gas, depending on the nature, shape and spread of the infrared absorption spectrum, the fixed pass band filters should be designed with precision, to ensure the minimum temperature-related response between the signal and the reference detector channel.

For the six gases of interest, the specifications drawn from the model results are tabulated in Table 3 below.

Table 3. Modelled ideal fixed filter specifications for both signal and reference filters for the various gases of interest.

\begin{tabular}{|c|c|c|c|c|}
\hline \multicolumn{5}{|c|}{ (a): $\mathrm{CO}$} \\
\hline Filter & Central- $\lambda$ (um) & FWHM of Peak (um) & FWHM of Slope (um) & Transmission $\%$ \\
\hline Signal & 4.6 & 1 & 0.5 & 73 \\
\hline Reference & 4.665 & 0.5 & 0.5 & 73 \\
\hline \multicolumn{5}{|c|}{ (b): $\mathrm{NO}_{2}$} \\
\hline Filter & Central- $\lambda$ (um) & FWHM of Peak (um) & FWHM of Slope (um) & Transmission $\%$ \\
\hline Signal & 3.43 & 1 & 0.5 & 73 \\
\hline Reference & 3.495 & 0.5 & 0.5 & 73 \\
\hline \multicolumn{5}{|c|}{ (c): NH3 } \\
\hline Filter & Central- $\lambda$ (um) & FWHM of Peak $(\mu \mathrm{m})$ & FWHM of Slope $(\mu \mathrm{m})$ & Transmission $\%$ \\
\hline Signal & 3.0 & 1 & 0.5 & 73 \\
\hline Reference & 3.065 & 0.5 & 0.5 & 73 \\
\hline \multicolumn{5}{|c|}{ (d): $\mathrm{H}_{2} \mathrm{~S}$} \\
\hline Filter & Central- $\lambda$ (um) & FWHM of Peak $(\mu \mathrm{m})$ & FWHM of Slope $(\mu \mathrm{m})$ & Transmission $\%$ \\
\hline Signal & 3.98 & 1 & 0.5 & 73 \\
\hline Reference & 3.92 & 0.5 & 0.5 & 73 \\
\hline
\end{tabular}


Table 3. Cont.

\begin{tabular}{ccccc}
\hline \multicolumn{5}{c}{$(\mathbf{e}): \mathrm{CH}_{4}$} \\
\hline Filter & Central- $\lambda(\mathbf{u m})$ & FWHM of Peak $(\mu \mathrm{m})$ & FWHM of Slope $(\mu \mathrm{m})$ & Transmission $\%$ \\
\hline Signal & 3.33 & 3.0 & 2 & 73 \\
\hline Reference & 3.5 & 1.6 & 2 & 73 \\
\hline \multicolumn{7}{c}{ Filter } & Central- $\lambda(\mathbf{u m})$ & FWHM of Peak $(\mu \mathrm{m})$ & FWHM of Slope $(\mu \mathrm{m})$ & Transmission $\%$ \\
\hline Signal & 4.26 & 3.0 & 2 & 73 \\
\hline Reference & 4.6 & 1.6 & 2 & 73 \\
\hline
\end{tabular}

\subsection{Varying Pathlengths and Optical Throughputs}

For detection of moderately high to very high concentrations of gases which possess strong IR-absorption characteristics such as $\mathrm{CO}_{2}$ and $\mathrm{CH}_{4}$, the path length of the cell needs to be designed carefully to avoid saturation of the gas cell and avoid 100\% absorption. Impacts of varying path lengths and effects of using designs with different optical throughputs on gas detection, as well as the Signal-to-Noise ratio $(\mathrm{S} / \mathrm{N})$ of the sensor, were investigated by modelling for $\mathrm{CO}_{2}$ as shown in Figure 19 below, for varying path lengths and optical throughputs:

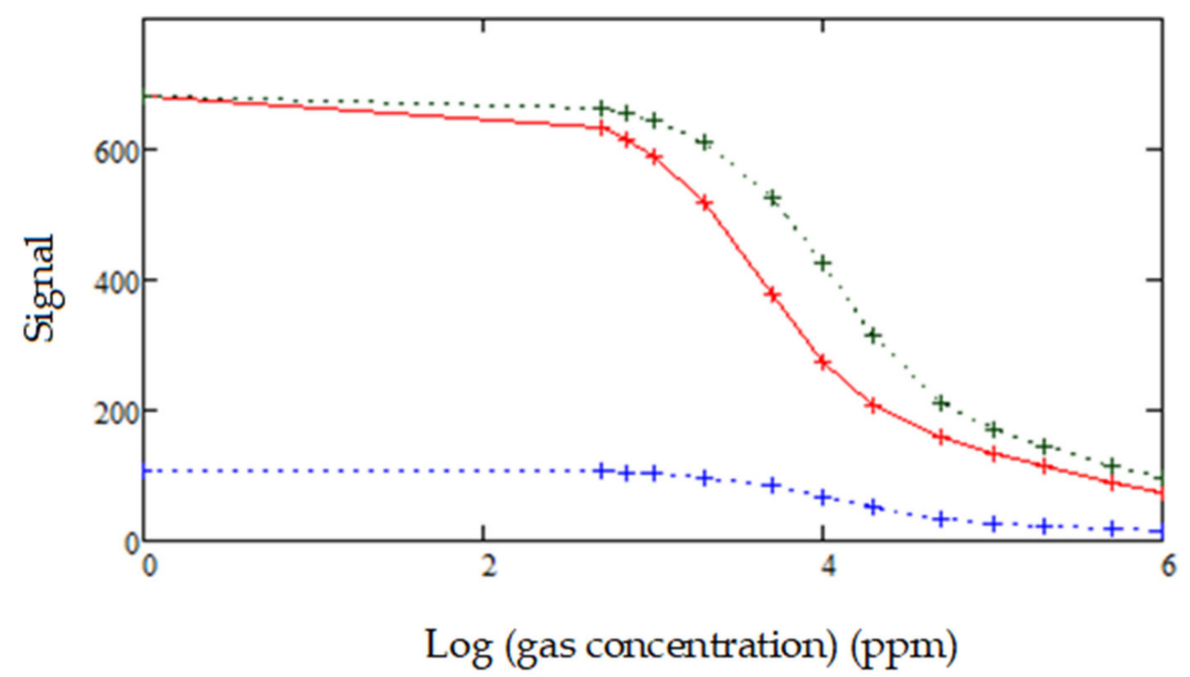

$$
\begin{aligned}
& \text { ++ PL: } 85 \mathrm{~mm} \text {, Optical Throughput: } 25 \% \\
& \text { +++ PL: } 32 \mathrm{~mm} \text {, Optical Throughput: } 4 \% \\
& \text { +++ PL: } 32 \mathrm{~mm} \text {, Optical Throughput: } 25 \%
\end{aligned}
$$

Figure 19. Detectable signal modelled for different path length-optical throughput combinations for $\mathrm{CO} 2$ gas concentrations upto $1,000,000 \mathrm{ppm}$.

For $\mathrm{CH}_{4}$ gas, the change of modelled output for various concentrations are compared for two different path lengths $60 \mathrm{~mm}$ and $90 \mathrm{~mm}$, as shown in Figure 20. Noise levels remaining the same, it is seen that the $\mathrm{S} / \mathrm{N}$ ratio increased almost 1.4 times for the $90 \mathrm{~mm}$ path length model, when compared to the $60 \mathrm{~mm}$ version, at low concentrations typical for methane detection. 


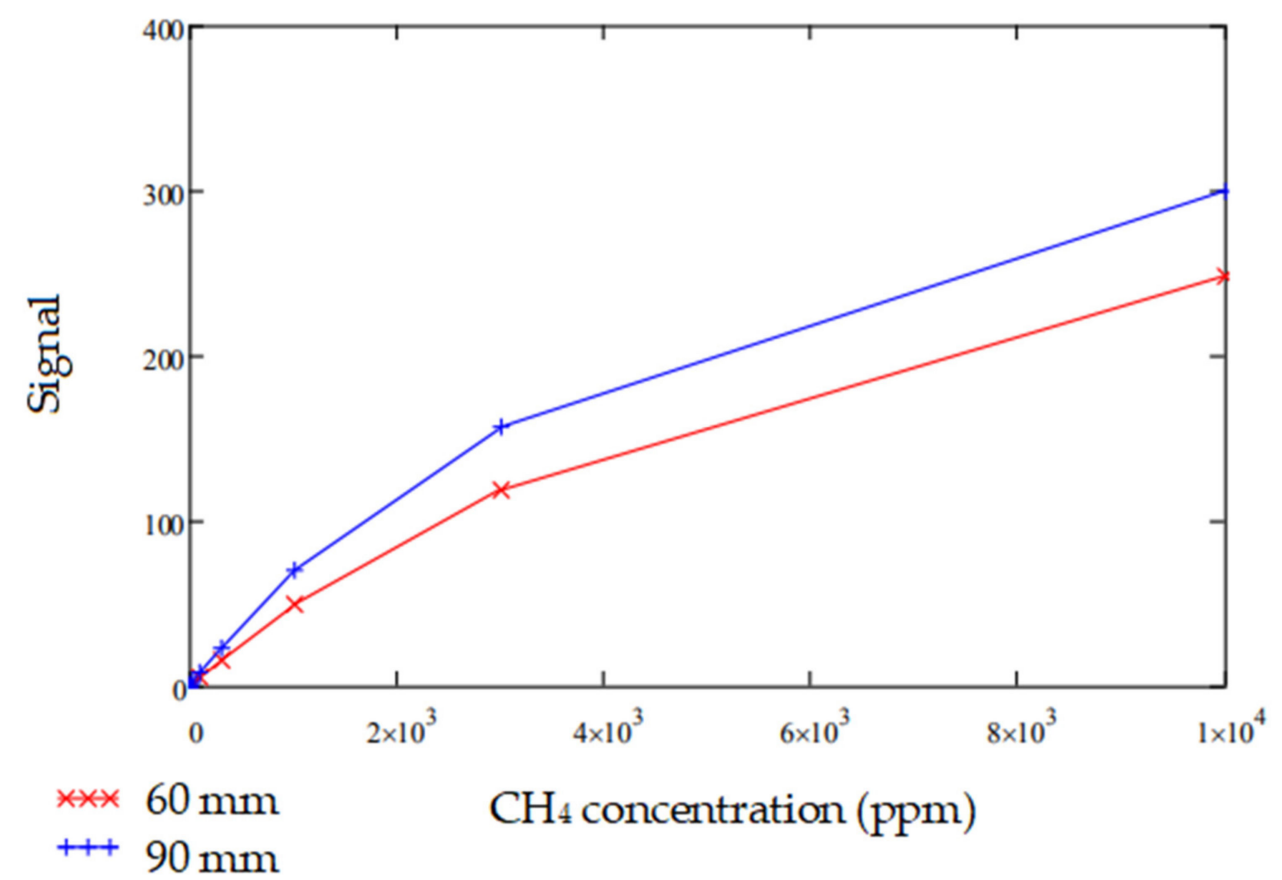

Figure 20. Change in signal modelled for different path lengths $60 \mathrm{~mm}$ and $90 \mathrm{~mm}$ for $\mathrm{CH}_{4}$ gas concentrations below 10,000 ppm.

\subsection{Measurement Accuracy for Various Gases}

The measurement accuracy for the various gases of interest are summarized in Table 4.

Table 4. Accuracy of gas measurements in \pm percentages of the measured value or $\pm p p m$ of measured ppm-for gases of interest and total measurement integration times.

\begin{tabular}{ccccccc}
\hline Target Gas ppm Range & $\mathbf{C O}_{\mathbf{2}}$ & $\mathbf{C H}_{\mathbf{4}}$ & $\mathbf{C O}$ & $\mathbf{N O}_{\mathbf{2}}$ & $\mathbf{H}_{\mathbf{2}} \mathbf{S}$ & $\mathbf{N H}_{\mathbf{3}}$ \\
\hline 0 to 1000 & $25 \mathrm{ppm}$ & $25 \mathrm{ppm}$ & $8 \%$ & $9.9 \%$ & $11.9 \%$ & $12.6 \%$ \\
1000 to 10,000 & $1 \%$ & $1 \%$ & $1.39 \%$ & $3.12 \%$ & $5.6 \%$ & $7.6 \%$ \\
10,000 to $1,000,000$ & $3 \%$ & $1.1 \%$ & $0.8 \%$ & $1 \%$ & $2.3 \%$ & $4.8 \%$ \\
Integration time (s) & $1 \mathrm{~s}$ & $1 \mathrm{~s}$ & $4 \mathrm{~min}$ & $4 \mathrm{~min}$ & $42 \mathrm{~min}$ & $43 \mathrm{~min}$ \\
\hline
\end{tabular}

\section{Conclusions and Future Work}

In this work, we have demonstrated a novel NDIR-based gas sensor design with a folded optics arrangement providing a $60 \mathrm{~mm}$ pathlength with a single broadband light source/detector array optopair providing efficient simultaneous detection of up to six gases $\left(\mathrm{CO}_{2}, \mathrm{CH}_{4}, \mathrm{CO}, \mathrm{NO}_{2}, \mathrm{H}_{2} \mathrm{~S}\right.$, $\mathrm{NH}_{3}$ ) with detection levels aligned with commercial use. The infrared source/detector array optopair, optics, and processing electronics were characterized and modelled to understand limitations and areas for improvements in signal acquisition, temperature sensitivities, signal corrections including processing techniques, integration time, calibration algorithms, optical filter spectral characteristics. Experiments have demonstrated that the micro-hotplate source can be driven using very short current pulses, effectively reducing power consumption into the $\mathrm{mJ}$ range. Modelling indicates energy consumption per measurement is typically $13 \mathrm{~mJ}$ for a $\pm 3 \%$ gas detection measurement accuracy.

A C ++ based data acquisition system and a Python-based post-processing tool was developed and used to extract of the microcontroller data from the sensor using a serial USART interface and real time data acquisition. The signal processing is presently done outside the sensor unit, which restricts the pulsing frequency of the hot plate source due to the slowness of acquisition. Future work will focus on enhancing measurement accuracy by improving/shaping the source pulsing characteristics. Also, a next stage to this work will be to incorporate the signal processing into the microcontroller, making the 
sensor completely stand-alone and incorporating temperature calibration and compensation algorithms into the firmware.

Author Contributions: Conceptualization, D.G., D.H. and E.W.; methodology, M.M., D.H.; software, M.M., D.H.; validation, M.M., D.H. and S.S.; formal analysis, M.M., D.H., E.W. and S.S.; investigation, M.M., D.H.; resources, D.G.; data curation, M.M., D.H., E.W. and S.S.; writing—original draft preparation, M.M., D.H. and D.G.; writing-review and editing, D.G. and S.A.; visualization, S.A.; supervision, D.H. and D.G.; project administration, D.H. and D.G.; funding acquisition, D.H. and D.G. All authors have read and agreed to the published version of the manuscript.

Funding: This research was funded by a Scottish Universities Physics Alliance Ph.D. studentship, Scottish Enterprise High Growth Start-Up and Censis Innovation Centre funding.

Acknowledgments: The authors acknowledge supply of hotplates from Semefab Ltd., Glenrothes, Scotland.

Conflicts of Interest: The authors declare no conflict of interest.

\section{References}

1. Krier, A. Mid-Infrared Semiconductor Optoelectronics; Krier, A., Ed.; Springer: New York, NY, USA, 2006.

2. Wong, J.Y. NDIR Gas Sensor. U.S. Patent 5,834,777, 1995.

3. Stuart, B.H. Infrared Spectroscopy: Fundamentals and Applications (Analytical Techniques in the Sciences (AnTs)); John Wiley and Sons: Hoboken, NJ, USA, 2004; ISBN 978-0-470-85428-6.

4. Miller, J.L. Principles of Infrared Technology: A Practical Guide to the State of the Art, 1st ed.; Springer: New York, NY, USA, 2001; ISBN 978-0-412-09861-1.

5. Popa, D.; Udrea, F. Towards Integrated Mid-Infrared Gas Sensors. Sensors 2019, 19, 2076. [CrossRef] [PubMed]

6. Du, Y.; Peng, Z.; Ding, Y. High-accuracy sinewave-scanned direct absorption spectroscopy. Opt. Express 2018, 26, 29550. [CrossRef] [PubMed]

7. Liu, K.; Mei, J.; Zhang, W.; Chen, W.; Gao, X. Multi-resonator photoacoustic spectroscopy. Sens. Actuators B Chem. 2017, 251, 632-636. [CrossRef]

8. Ma, Y. Review of Recent Advances in QEPAS-Based Trace Gas Sensing. Appl. Sci. 2018, 8, 1822. [CrossRef]

9. Vergara, A.; Vembu, S.; Ayhan, T.; Ryan, M.A.; Homer, M.L.; Huerta, R. Chemical gas sensor drift compensation using classifier ensembles. Sens. Actuators B Chem. 2012, B166-B167, 320-329. [CrossRef]

10. Hauptmann, P. Sensors: Principles \& Application, 201st ed.; Prentice Hall Inc.: Englewood Cliffs, NJ, USA, 1993.

11. Korotcenkov, G. Metal oxides for solid-state gas sensors: What determines our choice? Mater. Sci. Eng. B 2007, 139, 1-23. [CrossRef]

12. Williams, D.E. Conduction and gas response of semiconductor gas sensors Solid State Gas Sensors. In Solid State Gas Sensors, (Adam Hilger Series on Sensors); Tofield, B.C., Ed.; CRC Press: Bristol, UK, 1987.

13. Bakker, E.; Telting-Diaz, M. Electrochemical Sensors. Anal. Chem. 2002, 74, 2781-2800. [CrossRef] [PubMed]

14. Esler, M.B.; Griffith, D.W.T.; Wilson, S.R.; Steele, L.P. Precision Trace Gas Analysis by FT-IR Spectroscopy. 1. Simultaneous Analysis of $\mathrm{CO}_{2}, \mathrm{CH}_{4}, \mathrm{~N}_{20}$, and $\mathrm{CO}$ in Air. Anal. Chem. 2000, 72, 206-215. [CrossRef] [PubMed]

15. Radwan, L. Infrared $\mathrm{CO}_{2}$ analysis in expired air as a test of the pulmonary function. I. Evaluation of the capnographic curve. Pol. Med. J. 1976, 6, 403-411. [PubMed]

16. Apte, M.G. A Review of Demand Controlled Ventilation; Universidade de Porto: Porto, Portugal, 2006.

17. Gravenstein, J.S.; Jaffe, M.B.; Gravenstein, N.; Paulus, D.A. Capnography, 2nd ed.; Cambridge University Press: Cambridge, UK, 2011; ISBN 9780511933837.

18. Gupta, S.; Khare, M.; Goyal, R. Sick building syndrome-A case study in a multistory centrally air-conditioned building in the Delhi City. Build. Environ. 2007, 42, 2797-2809. [CrossRef]

19. Jennings, P.R.; Fahringer, D.; Collins, T. Sick building syndrome. Indoor air quality and your patients' health. JAAPA 2000, 39, 34-36.

20. Information Administration-US Department of Energy, D.I.-0384. Energy Rev. 2009; 2010. Available online: http://www.eia.gov/aer (accessed on 9 July 2020).

21. Van Gastelen, S.; Dijkstra, J. Prediction of methane emission from lactating dairy cows using milk fatty acids and mid-infrared spectroscopy. J. Sci. Food Agric. 2016, 96, 3963-3968. [CrossRef] [PubMed]

22. Gibson, D.; MacGregor, C. A Novel Solid State Non-Dispersive Infrared $\mathrm{CO}_{2}$ Gas Sensor Compatible with Wireless and Portable Deployment. Sensors 2013, 13, 7079-7103. [CrossRef] [PubMed] 
23. Liu, H.; Chu, R.; Tang, Z. Metal Oxide Gas Sensor Drift Compensation Using a Two-Dimensional Classifier Ensemble. Sensors 2015, 15, 10180-10193. [CrossRef] [PubMed]

24. Gibson, D.; Waddell, E. Miniaturised Infrared Spectrophotometer. Patent Application Number GB1702480.3, 15 February 2018.

25. Welfor, W.T.; Winston, R. High Collection Nonimaging Optics; Academic Press: Cambridge, MA, USA, 1989.

26. Wang, C.H.; Crowder, J.G.; Smith, S.D.; Bramley, P.; Vass, A. Comparison of IR LED gas sensors with thermal source products. IEE Proc. Optoelectron. 1997, 144, 266-270. [CrossRef]

27. Elmi, I.; Zampolli, S.; Cozzani, E.; Passini, M.; Cardinali, G.C.; Severi, M. Development of Ultra Low Power Consumption Hotplates for Gas Sensing Applications. In Proceedings of the 2006 th IEEE Conference on Sensors, Daegu, Korea, 22 October 2006; pp. 243-246.

28. Cozzani, E.; Roncaglia, A.; Zampolli, S.; Elmi, I.; Mancarella, F.; Tamarri, F.; Cardinali, G.C. Material Properties Measurement and Numerical Simulation for Characterization of Ultra-Low-Power Consumption Hotplates. In Proceedings of the TRANSDUCERS 2007-2007 International Solid-State Sensors, Actuators and Microsystems Conference, Lyon, France, 10 June 2007; pp. 1661-1664.

29. Kharbanda, D.; Khanna, P.K.; Shekhar, C.; Mohan, A. Design, simulation and modelling of LTCC based micro hotplate for gas sensor applications. In Proceedings of the 2012 1st International Symposium on Physics and Technology of Sensors (ISPTS-1), Maharashtra, India, 8 March 2012; pp. 257-260.

30. Moss, T.S. Lead Salt Photoconductors. IRE 1955. [CrossRef]

31. Downs, C.; Vandervelde, T. Progress in Infrared Photodetectors Since 2000. Sensors 2013, 13, 5054-5098. [CrossRef] [PubMed]

32. Song, S.; Gibson, D.; Hutson, D. Apparatus and Methods for Depositing Variable Interference Filters. Patent Number WO 2018/150173, 23 August 2018.

33. Li, C.; Song, S.; Gibson, D.; Child, D.; Chu, H.; Waddell, E. Modeling and validation of uniform large-area optical coating deposition on a rotating drum using microwave plasma reactive sputtering. Appl. Opt. 2017, 56, C65-C70. [CrossRef] [PubMed]

34. Song, S.; Li, C.; Chu, H.O.; Gibson, D. Reactive dynamics analysis of critical Nb_2O_5 sputtering rate for drum-based metal-like deposition. Appl. Opt. 2017, 56, C206. [CrossRef] [PubMed]

35. HITRAN (High-Resolution Transmission Molecular Absorption Database). Available online: http://www.cfa. harvard.edu/hitran/ (accessed on 7 May 2020).

36. Wang, P.; Fu, X.; Gibson, D.; Fleming, L.; Ahmadzadeh, S.; Li, C.; Muhiyudin, M.; Song, S.; Hutson, D.; Moodie, D.; et al. Optimised Performance of Non-Dispersive Infrared Gas Sensors Using Multilayer Thin Film Bandpass Filters. Coatings 2018, 8, 472. [CrossRef]

37. Northumbria Optical Coatings Ltd. Available online: https://www.noc-ltd.com/products/narrow-bandpass (accessed on 22 June 2020).

(C) 2020 by the authors. Licensee MDPI, Basel, Switzerland. This article is an open access article distributed under the terms and conditions of the Creative Commons Attribution (CC BY) license (http://creativecommons.org/licenses/by/4.0/). 